\title{
Complementary Multianalytical Approach To Study the Distinctive Structural Features of the Main Humic Fractions in Solution: Gray Humic Acid, Brown Humic Acid, and Fulvic Acid
}

\author{
Roberto Baigorri, ${ }^{*}{ }^{\dagger}$ Marta Fuentes,${ }^{\S}$ Gustavo González-Gaitano, ${ }^{\S}$ \\ José M. García-Mina, ${ }^{\dagger, \S}$ GonZAlo Almendros, ${ }^{\#}$ AND \\ FRANCISCO J. GONZÁLEZ-VILA ${ }^{\perp}$

\begin{abstract}
CIPAV-Roullier Group, Polígono Arazuri-Orkoien, 31160 Orkoien, Spain; Department of Chemistry and Soil Science, University of Navarra, 31080 Pamplona, Spain; Centro de Ciencias

Medioambientales, CSIC, Serrano 115B, 28006 Madrid, Spain; and Instituto de Recursos Naturales y Agrobiología, CSIC, P.O. Box 1052, 41080 Sevilla, Spain
\end{abstract}

\begin{abstract}
Previous studies have indicated that the main fractions of humic substances (HS), gray humic acid (GHA), brown humic acid (BHA), and fulvic acid (FA), present different molecular patterns in water solution that are probably associated with specific structural features. However, the techniques used in these previous studies did not permit clarification of the principal qualitative characteristics of these structures. To study more in depth this subject several GHA, BHA, and FA have been analyzed through the complementary use of UV-visible and FTIR spectroscopy, ${ }^{13} \mathrm{C} N M R$, thermogravimetry, and pyrolysis GC-MS. The results indicate that the studied humic fractions have different and distinctive structural features. Thus, large and nonpolar structural units (paraffins, olefins, terpenes) and aliphatic structures seem to accumulate in the gray fraction, whereas the smallest and more polar (furfural, phenols) and simpler structural units (sugar- and amino acid-related structures) are present in the fulvic one. BHA has a higher content in polycyclic aromatic moieties, S-containing compounds and aromatic structures, thus suggesting the presence of more condensed aromatic rings. Likewise, differences in both the presence of polar groups and the apparent molecular size explain the pattern of solubility as a function of $\mathrm{pH}$ and ionic strength $(I)$ that defines each HS fraction. These results also indicate that the structural differences among the HS fractions are not only quantitative (the presence of the same type of structures differing in size and the concentration of functional groups) but also qualitative, because each fraction presented different and distinctive structural domains. These structural domains explain the molecular patterns associated with each $\mathrm{HS}$ fraction. Thus, the presence of smaller and more O-functionalized structural units including aromatic domains in FA explain their tendency to form molecular aggregates (hydrogen bridges, metal bridges, and hydrophobic interactions) in solution. This fact could also explain the presence of molecular aggregates in BHA, although to a lesser extent than in FA. Finally, the dominant aliphatic and less functionalized character of GHA may justify its lower tendency to form aggregates in solution at neutral and alkaline $\mathrm{pH}$. Likewise, the results also indicate that the different structural domains associated with these fractions may be the consequence of diverse biosynthetic pathways involving different precursors.
\end{abstract}

KEYWORDS: Humic substances; gray and brown humic acid; fulvic acid; pyrolysis GS-MS; thermogravimetry

\section{INTRODUCTION}

An adequate comprehension of the chemical nature of humic substances (HS) is fundamental to better understand both carbon

* Corresponding author (telephone 34948 324752; fax 34948 324032; e-mail rbaigorri@timacagro.es).

†olígono Arazuri-Orkoien.

$\S$ University of Navarra. cycle ( 1 ) and many physicochemical processes occurring in soils (2). A number of studies have shown that HS are very complex and heterogeneous molecular systems (3). In fact, the definition of HS is rather ambiguous in chemical or structural terms, and their classification is principally related to procedures of

\footnotetext{
\# Centro de Ciencias Medioambientales, CSIC.

${ }^{\perp}$ Instituto de Recursos Naturales y Agrobiología, CSIC.
} 
separation and fractionation as a function of their different solubilities with variations of $\mathrm{pH}$ and ionic strength $(I)$. Thus, gray humic acids (GHA) are soluble in alkaline media and low $I$ values, brown humic acids (BHA) are soluble in alkaline conditions independent of $I$ values $(1,4-6)$, and fulvic acids (FA) are soluble independent of $\mathrm{pH}$ and $I$. A number of works principally based on the study of each HS fraction using qualitative indices derived from UV-visible spectroscopy, such as the E4/E6 ratio or RF, suggest the presence of specific and different structural domains in BHA and GHA (6). Other studies based on porosimetry and size distribution supported this conclusion (7-12).

A previous research carried out in our laboratory involving complementary analytical techniques (ultrafiltration, transmission electron microscopy, confocal microscopy, fluorescence spectroscopy, and ${ }^{13} \mathrm{C}$ NMR) indicated that these humic fractions corresponded to different molecular patterns (11). Thus, GHA presented a dominant macromolecular pattern and aliphatic character; BHA showed both a macromolecular and a supramolecular pattern, with a significant aromatic character, and finally FA mainly exhibited a supramolecular behavior, with the presence of differently substituted aromatic structures (11). Likewise, the apparent molecular size decreased in the order GHA $>$ BHA $>$ FA (11). The results suggested that these different HS fractions probably have specific and singular structural features. However, the conclusions derived from the ${ }^{13} \mathrm{C}$ NMR study are not totally conclusive as certain studies indicate that this technique could over- or underestimate some properties such as aromaticity and aliphaticity (13). More recently, another study involving the multistatistical analysis (Paretto analysis) of MS spectra of several GHA, BHA, and FA showed that these HS fractions corresponded to specific and different patterns of molecular ion distribution, thus also suggesting specific structural patterns for each HS fraction (14). However, little information on the structural features of these HS structural groups could be derived from this study.

In this context, the complementary use of potentiometric analysis, UV-visible-FTIR spectroscopies, pyrolysis GC-MS, and thermogravimetry can be of great value to both complete the information obtained from ${ }^{13} \mathrm{C}$ NMR and characterize the aromatic and aliphatic moieties in these HS fractions. Likewise, this study can also contribute to the explanation of the dominant molecular patterns present in the different HS fractions in structural terms.

\section{MATERIALS AND METHODS}

Humic Materials. Soil humic acids from different origins were used in this study: a young brown coal humic acid (leonardite) extracted from a soil sample of Czech Republic (ZHA) (15), a commercial humic acid from Aldrich Chemical (AHA), and a Leonardite Standard Humic Acid (LHA) purchased from the International Humic Substances Society (IHSS). Two fulvic acids from IHSS standards were included in this work: Suwannee River Reference Fulvic Acid (SRFA) and Waskish Peat Reference Fulvic Acid (WRFA).

Extraction Procedure. The different HS were isolated and purified following the IHSS procedure $(1,16)$ and freeze-dried. IHSS standards did not need this treatment. Humic acids (HA) were fractionated in GHA and BHA fractions according to the method of Swift (4). Briefly, we dissolved $12 \mathrm{~g} / \mathrm{L}$ of $\mathrm{HA}$ in $2 \mathrm{M} \mathrm{KCl}$ at $\mathrm{pH} 7$. After $12 \mathrm{~h}$ of continuous stirring, the suspension was centrifuged (7650 $\mathrm{g}$ of centrifugal force). The solution containing BHA and the precipitate containing GHA were purified following the IHSS procedure $(1,16)$ until the ash contents were $<2 \%$. The samples were named as follows: AGHA (Aldrich gray humic acid), ABHA (Aldrich brown humic acid), LGHA (Leonardite Standard gray humic acid), LBHA (Leonardite Standard brown humic acid), ZGHA (Czech gray humic acid), ZBHA (Czech brown humic acid), WPFA (Waskish Peat Reference Fulvic Acid), and SRFA (Suwannee River Reference Fulvic Acid).

UV-Visible Study. The RF and $\Delta \log K$ parameters were obtained following the procedure described by Kumada (6). The HA fractions were diluted to $1 \%$ in $0.1 \mathrm{M} \mathrm{NaOH}$. The RF was calculated as $K_{600} \times$ $1000 / C$, where $K_{600}$ is the optical density of HA solution at $600 \mathrm{~nm}$ and $C$ is the milliliters of $0.1 \mathrm{M} \mathrm{KMnO}_{4}$ consumed in the oxidation of $30 \mathrm{~mL}$ of the HA solution. On the other hand, $\Delta \log K$ is defined as $\log K_{400}-\log K_{600}$, where $\log K_{400}$ and $\log K_{600}$ are the logarithms of the optical density of HA solution at 400 and $600 \mathrm{~nm}$, respectively.

Potentiometric Titrations. Potentiometric titrations were carried out on solutions prepared by dissolving an adequate amount of lyophilized HS fractions in $0.1 \mathrm{M} \mathrm{NaOH}$. Once the HS has been dissolved, an $\mathrm{H}^{+}$-cationic exchange resin (Amberlite IRA- $118 \mathrm{H}^{+}$) was added to the stock solution to attain a final $\mathrm{pH}$ of 3.5. The resin was then separated by centrifugation ( $15 \mathrm{~min}$ at $5000 \mathrm{~g}$ of centrifugal force). To carry out the titration studies, an aliquot of the stock solution corresponding to $50 \mathrm{mg}$ of the molecular system was added to a water solution containing $0.5 \mathrm{~mL}$ of $0.1 \mathrm{M} \mathrm{HClO}_{4}$ and the required volumes of $1 \mathrm{M} \mathrm{KNO}_{3}$ for fixing ionic strength $(I)$ values $(0.01 \mathrm{M})$. The final volume was $35 \mathrm{~mL}$. The solution was titrated with $0.05 \mathrm{~mL}$ increments of $0.1 \mathrm{M} \mathrm{NaOH}$ by using a Metrohm Titrando 809 under $\mathrm{N}_{2}$ atmosphere, and the $\mathrm{pH}$ was registered by means of a combined $\mathrm{pH}$ glass electrode of the same company. To ensure that equilibrium between measurements has been reached, no base was added until the $\mathrm{pH}$ measurement remained stable with a variation of $\mathrm{pH}$ no greater than $0.01 \mathrm{pH}$ unit over 5 min. The experimental data were treated following the method of analysis of functional groups described by Gerard et al. (17).

FTIR Spectroscopy. Pellets were prepared by mixing $1 \mathrm{mg}$ of each freeze-dried sample with $100 \mathrm{mg}$ of $\mathrm{KBr}$ to homogenization. Infrared spectra were recorded on these pellets with a Nicolet Magna-IR 550 spectrometer over the $4000-400 \mathrm{~cm}^{-1}$ range, with a resolution of 2 $\mathrm{cm}^{-1}$

Solid-State ${ }^{13} \mathrm{C}$ NMR Spectroscopy. Solid-state ${ }^{13} \mathrm{C}$ NMR spectra were obtained on a Bruker Avance AV-400WB (9.4 T) spectrometer at $100.47 \mathrm{MHz}$ using the cross-polarization magic angle spinning technique (CPMAS), with a spinning speed of $12 \mathrm{kHz}, 90^{\circ}$ pulse width, $30 \mathrm{~ms}$ acquisition time, and $4.0 \mathrm{~s}$ delay.

Thermogravimetric Analysis (TGA). Thermogravimetric studies were carried out heating continuously from 25 to $1450{ }^{\circ} \mathrm{C}$ at a heating rate of $10{ }^{\circ} \mathrm{C} \min ^{-1}$. The TGA curves were recorded on a Mettler Toledo thermoanalyzer TGA/SDTA851. The peaks were deconvoluted with the software PeakFit v4.12 (SeaSolve Software Inc., 2003).

Pyrolysis GC-MS. Pyrolysis GC-MS was performed on an Agilent 6890 Network gas chromatographic system coupled to an Agilent 5973 Network mass selective detector (electron impact at $70 \mathrm{eV}$ ). The column (fused silica, $30 \mathrm{~m} \times 0.25 \mathrm{~m} \times 0.25 \mathrm{~mm}$ ) was coated with DB5MS. About $0.5 \mathrm{mg}$ of sample was loaded in the cup of a PY2020iD pyrolyzer (Frontier Laboratory Ltd.) and heated at $500{ }^{\circ} \mathrm{C}$ for $1 \mathrm{~min}$. The pyrolysis products were injected directly through a deactivated needle inserted in the GC-MS injector. The GC injector temperature was $250{ }^{\circ} \mathrm{C}$, and the interface between the pyroprobe and the GC system was kept at $350{ }^{\circ} \mathrm{C}$. The temperature program was as follows: from 50 to $100{ }^{\circ} \mathrm{C}$ at a rate of $30{ }^{\circ} \mathrm{C} \mathrm{min}-1$ and from 100 to 300 at $10{ }^{\circ} \mathrm{C} \mathrm{min}-1$

Statistical Analysis. All statistical analyses have been made by Statistica v6.0 software (StatSoft, Inc., 1984-2001). Pearson coefficients were used for correlation data.

\section{RESULTS AND DISCUSSION}

The results concerning acid group concentration of the different HS fractions studied are presented in Table 1. In general, the results obtained were in line with those previously reported (1). Thus, the acidity and oxygen-containing functional group concentration obtained by potentiometry follows the order FA $>$ BHA > GHA (Table 1). This result is in line with previous results related to the elemental composition of the different humic fractions obtained using elemental analysis (11).

With regard to the UV-visible study, both $\Delta \log K$ and RF indices were calculated and plotted according to the method of 
Table 1. Functional (Potentiometry) Analysis of the Different Humic Fractions $^{a}$

\begin{tabular}{lcccc}
\hline & \multicolumn{4}{c}{ acidity $(\mathrm{mmol} / \mathrm{g}$ of HS) } \\
\cline { 2 - 5 } & strong acidity & COOH & phenolic $\mathrm{OH}$ & total acidity \\
\hline AGHA & 0.10 & 0.90 & 0.48 & 1.48 \\
ABHA & 0.50 & 1.83 & 1.15 & 3.48 \\
LGHA & 0.14 & 0.30 & 0.25 & 0.69 \\
LBHA & 0.20 & 2.16 & 1.14 & 3.50 \\
ZGHA & 0.12 & 1.42 & 0.71 & 2.25 \\
ZBHA & 0.33 & 2.22 & 0.98 & 3.54 \\
WPFA & 1.18 & 1.72 & 0.86 & 3.76 \\
SRFA & 1.56 & 2.13 & 0.93 & 4.62 \\
\hline
\end{tabular}

${ }^{a}$ AGHA, Aldrich gray humic acid; ABHA, Aldrich brown humic acid; LGHA, Leonardite gray humic acid; LBHA, Leonardite brown humic acid; ZGHA, Czech gray humic acid; ZBHA, Czech brown humic acid; WPFA, Waskish Peat Fulvic Acid; SRFA, Suwannee River Fulvic Acid.

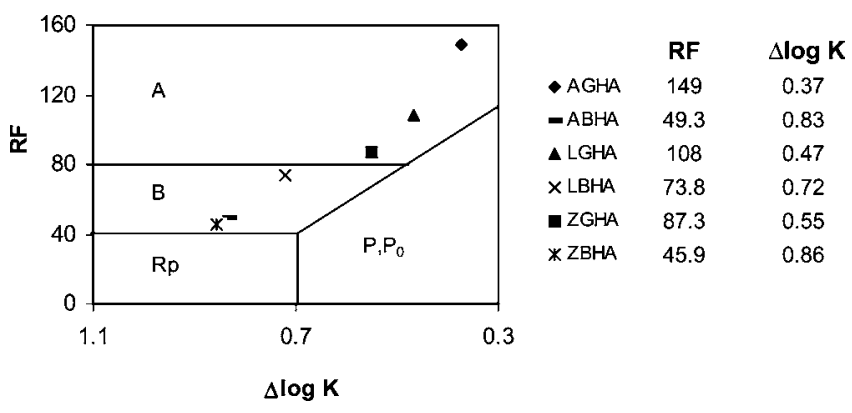

Figure 1. Kumada classification diagram of different humic fractions.

Kumada (6) (Figure 1). When compared with Kumada HS classification, GHA are similar to A-type HA, whereas BHA corresponded to B-type HA class. Kumada used this classification to establish differences between humic acids with different origins, but our results show that it is also of interest to differentiate between brown and gray humic fractions. In general, RF values for GHA were higher than those of BHA, which may indicate not only a higher humification degree in GHA but also differences in the humification pathways for both HA fractions. Likewise, these results are compatible with the presence of different structural domains in the considered HS fractions.

The FTIR spectroscopy data also indicated the presence of different structural domains for each HS fraction studied. Although FTIR is a classical technique for HS characterization $(18-25)$, the information it provides is rather qualitative and less straightforward than that obtained with other techniques. This is due to the number of absorption bands that may overlap in a specific region of the spectrum. Most authors agree on the assignation of the absorption bands for the different functional groups (Table 2; Figure 2). In general, the BHA fraction strongly absorbed in the aromatic $\left(1620 \mathrm{~cm}^{-1}\right)$, carboxylic $(1700$ $\mathrm{cm}^{-1}$ ), and hydroxyl stretching $\left(3400-3200 \mathrm{~cm}^{-1}\right.$ ) regions, more than the other fractions, whereas for FA fractions the carboxylic and hydroxyl regions are the most absorbing ones. These results are in line with those obtained from potentiometry.

The GHA fraction displayed a fair absorption in the typical absorption regions for alcohols $\left(1170 \mathrm{~cm}^{-1}\right)$ and aliphatic methylene groups $\left(2930-2850 \mathrm{~cm}^{-1}\right)$. These bands are scarce or did not appear in either BHA or FA fractions. These results indicate that GHA presents more aliphatic character than BHA and FA. Shin et al. (21) and Tanaka et al. (24) have reported a similar pattern in humic fractions of high molecular weight in comparison with fractions of low molecular weight. According to Chen et al. (26), an aliphaticity/aromaticity index may be obtained from the $2900-2950 / 1600-1620 \mathrm{~cm}^{-1}$ ratio. The results obtained (Table 2) showed higher values of this ratio for GHA in comparison with BHA and FA, whereas there were no clear differences between BHA and FA. These results indicate a dominant aliphatic character for GHA and a significant aromatic one for BHA and FA.

To study more in depth the features of these structural domains we applied TGA and pyrolysis GC-MS analysis to the different HS fractions.

A number of investigations have shown that in thermogravimetric studies (differential thermogravimetry, DTA) of HS the following temperature ranges can be distinguished: dehydration (interval I), from 70 to $110{ }^{\circ} \mathrm{C}$; degradation of aliphatic structures and polysaccharides (interval II), from 210 to 380 ${ }^{\circ} \mathrm{C}$; decarboxylation (interval III), from 380 to $460{ }^{\circ} \mathrm{C}$; and degradation of more refractory structures, such as aromatic rings and aromatic condensates (interval IV), up to $650{ }^{\circ} \mathrm{C}(25-29)$.

The TGA data of the studied HS fractions are presented in Table 3. All fractions showed a peak at around $100{ }^{\circ} \mathrm{C}$ (interval I) that corresponds to the typical water loss of these substances. Likewise, all of them display a peak within interval II that can be associated with the decomposition of aliphatic-type and polysaccharide structures. In the case of GHA fractions the peak represents the highest percentage of mass loss, in relation to total mass loss. This reflects the important aliphatic character of GHA. However, the relative importance of this peak in BHA

Table 2. Main FTIR Absorption Bands of the Different Humic Fractions and Their Relative Intensity in Each Fraction and the $2930 \mathrm{~cm}^{-1} / 1610 \mathrm{~cm}^{-1}$ Ratio

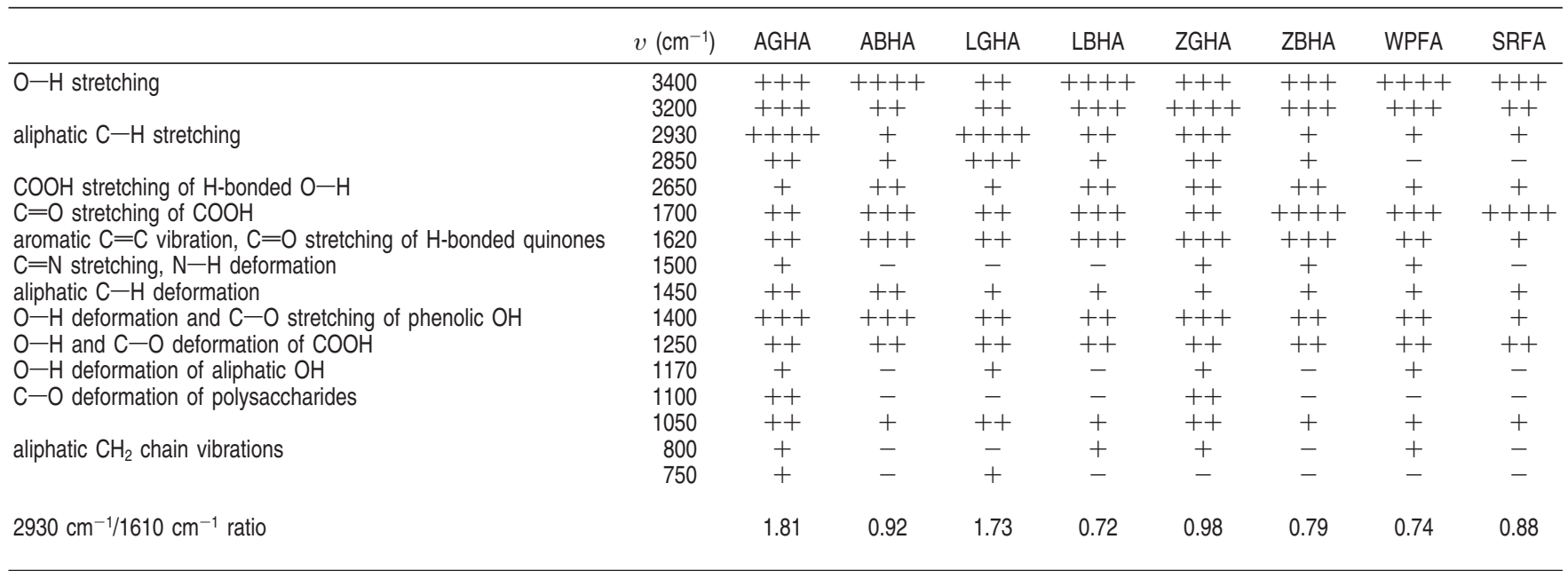



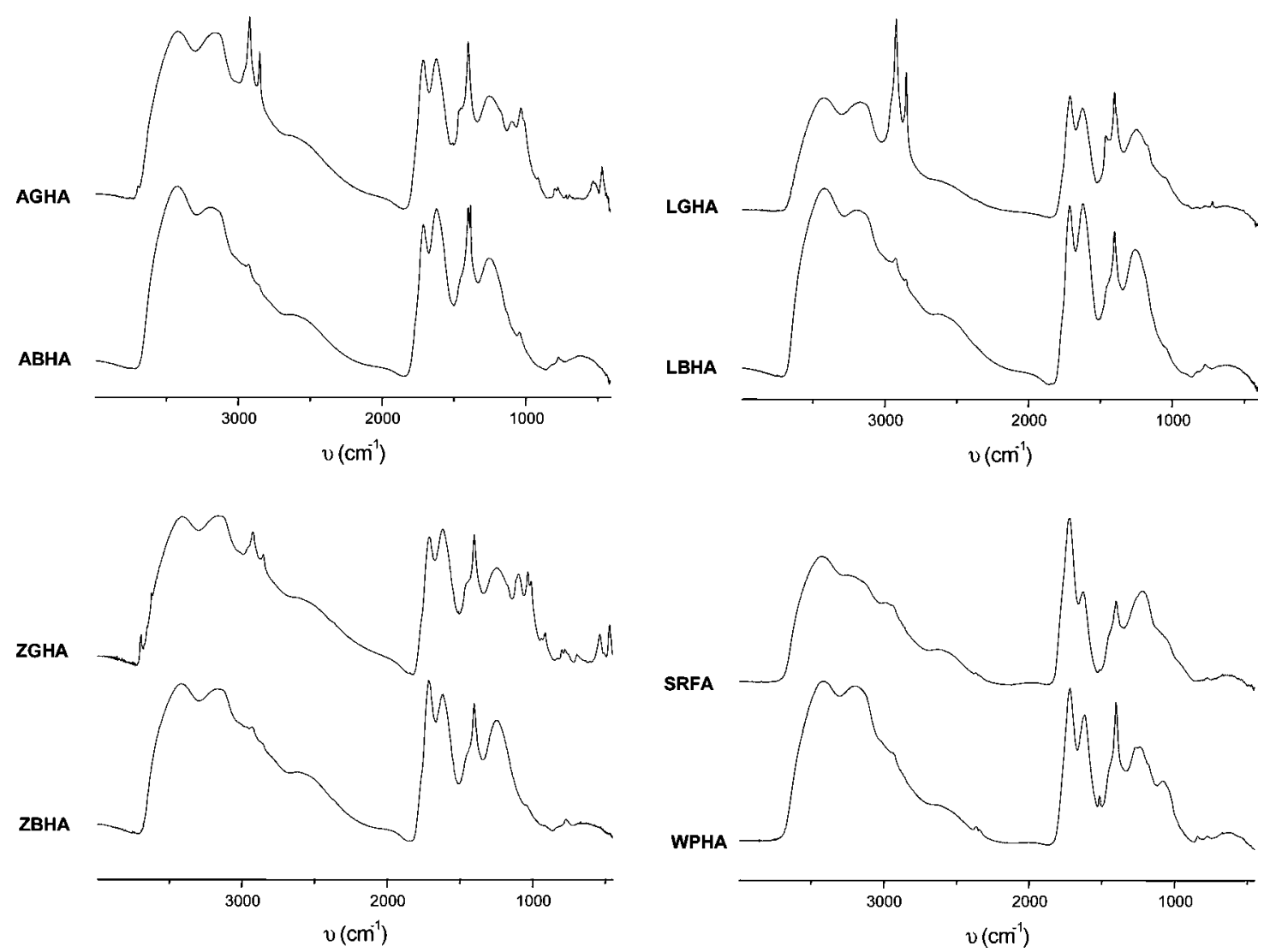

Figure 2. FTIR spectra of the different humic fractions.

Table 3

(A) Temperature Values $\left({ }^{\circ} \mathrm{C}\right)$ for the Peaks in the Different TGA Intervals for the Humic Fractions ${ }^{a}$

\begin{tabular}{|c|c|c|c|c|}
\hline & range I & range II & range III & range IV \\
\hline AGHA & 100 & 365 & 425 & nd \\
\hline $\mathrm{ABHA}$ & 101 & 276 & 417 & 507 \\
\hline LGHA & 70.8 & 365 & 430 & nd \\
\hline LBHA & 98.6 & 283 & 389 & 493 \\
\hline ZGHA & 101 & 324 & 442 & 480 \\
\hline ZBHA & 106 & 289 & 399 & 545 \\
\hline WPFA & 90.6 & 259 & 393 & 519 \\
\hline SRFA & 81.9 & 265 & 395 & 489 \\
\hline
\end{tabular}

(B) Mass Percent of Deconvoluted Peak for Chemical-Associated Structures

\begin{tabular}{|c|c|c|c|c|c|c|c|c|}
\hline & AGHA & $\mathrm{ABHA}$ & LGHA & LBHA & ZGHA & ZBHA & WPFA & SRFA \\
\hline water loss & 7.31 & 15.4 & 2.24 & 18.9 & 8.94 & 14.0 & 13.5 & 11.2 \\
\hline aliphatic-type and polysaccharide structures & 74.8 & 37.5 & 60.6 & 26.2 & 36.4 & 25.9 & 39.6 & 38 \\
\hline decarboxylation interval & 17.9 & 21.7 & 37.1 & 29.9 & 22.4 & 48.8 & 23.1 & 23.8 \\
\hline degradation of aromatic structures & & 25.4 & & 25.7 & 32.3 & 11.7 & 23.6 & 27.1 \\
\hline
\end{tabular}

${ }^{a}$ Range I, $70-110^{\circ} \mathrm{C}$; range II, $210-380{ }^{\circ} \mathrm{C}$; range III, $380-460{ }^{\circ} \mathrm{C}$; range IV, $460-650{ }^{\circ} \mathrm{C}$. nd, not determined.

was clearly lower than in GHA (Table 3B). It was also noteworthy that the temperature values corresponding to this peak were clearly higher for GHA than for BHA and FA (GHA $>$ BHA > FA) (Table 3A). This fact indicates a higher resistance to thermal decomposition for the aliphatic and polysaccharidetype structures present in GHA than for those present in BHA and FA. In principle, these results could be due to differences in both the humification degree of these humic types and/or their biosynthetic pathways.

In the decarboxylation interval (III), all of the samples showed peaks between 380 and $460{ }^{\circ} \mathrm{C}$. GHA are the fractions that exhibit peaks at higher temperatures within this interval (Table 3A). However, potentiometric results showed the lowest car- boxylic content for GHA (Table 1). This result may be related to the presence of a chemical and structural domain surrounding the carboxylic groups in GHA that protects them from decarboxylation, shifting the peak in the thermogram toward higher temperatures.

At higher temperatures (interval IV, degradation of aromatic structures), it can be noted that AGHA and LGHA displayed no peaks. This result corroborates the remarkable aliphaticity of these fractions as revealed by FTIR (Figure 2) and solidstate ${ }^{13} \mathrm{C}$ NMR spectroscopy (Table 4). In this sense, although ZGHA exhibited a peak in this temperature interval $\left(480{ }^{\circ} \mathrm{C}\right)$, its decomposition temperature was lower than that of the corresponding peak for $\mathrm{ZBHA}\left(545^{\circ} \mathrm{C}\right)$, thus suggesting more 
labile and less refractory aromatic structures in ZGHA. All BHA and FA samples presented this peak (Table 3A). In addition, BHA had a peak at $1100{ }^{\circ} \mathrm{C}$, which could be ascribed to black carbon formed by charring as a consequence of thermal condensation of secondary byproducts $(30-35)$ or the existence of black carbon derived material in humic substances present in soils $(36,37)$. This fact evidenced again the presence of more resistant aromatic structures in BHA with respect to GHA and FA. In summary, TG analysis showed the predominant aliphatic character of GHA and the aromatic one of principally BHA, but also that of FA.

Pyrolysis GC-MS is a suitable technique for deepening the study of the structure of the different HS fractions. The results obtained with this method are presented in Table 4, the first row including the selected pyrolytic markers $(38-45)$. As can be noted in this table, GHA accumulated the paraffin and olefin carbon, when compared with BHA. The total content of alkanes and alkenes (including terpenoids) was much higher in GHA than in BHA and practically negligible in FA. These results, besides confirming the dominant aliphatic character of GHA, also indicate that this aliphatic character probably has a lipidic origin because the pyrolytic and ${ }^{13} \mathrm{C}$ NMR markers for polysaccharides (PS and O-alkyl-C, respectively) are negligible. These conclusions are also supported by the correlation coefficients between pyrolysis GC-MS markers and ${ }^{13} \mathrm{C}$ NMR markers (Table 5). Thus, a very significant correlation between the aliphaticity measured by both pyrolysis GC-MS and ${ }^{13} \mathrm{C}$ NMR $(R=0.99)$ was obtained. Furthermore, a negative correlation between the aliphatic content measured by pyrolysis GCMS (higher in GHA) and the phenol-C content measured by ${ }^{13} \mathrm{C}$ NMR (higher in FA and BHA) $(R=-0.73)$ was also found. The fact that PS marker is very well correlated to carbonyl-C $\left({ }^{13} \mathrm{C}\right.$ NMR $)(R=0.91)$ suggests that this functionality in FA and BHA seems to be concentrated in the polysaccharide moiety.

With regard to phenols, alkylbenzenes, and polycyclic aromatic hydrocarbons (PAHs) (aromatic markers), they are concentrated in BHA, although phenols were also present in FA (Table 4). Thus, BHA and FA presented principally an aromatic character, although the qualitative characteristics of the aromaticity seem to be different between both groups. This result is in line with that obtained using ${ }^{13} \mathrm{C}$ NMR. In fact, the aromaticity measured by pyrolysis GC-MS is well correlated to arom-C content measured by ${ }^{13} \mathrm{C}$ NMR $(R=0.77)$ and also is negatively correlated with the aliphaticity measured by pyrolysis GC-MS and ${ }^{13} \mathrm{C}$ NMR $(R=-0.84$ and $R=-0.81$, respectively) (Table 5). Likewise, results obtained by pyrolysis GC-MS (principally concerning PHAs) also indicate the presence in BHA of an aromatic moiety containing more condensed structures than in the case of FA that present simpler aromatic rings but more functionalized (the presence of polar groups in the ring, such as phenols). These results are in line with those previously obtained using synchronous fluorescence spectroscopy (11).

With respect to the $\mathrm{N}$-containing groups it can be mentioned that the highest percentage is due to N-heterocycles (Table 4). These compounds, together with amines, concentrate in the fulvic fraction. In principle, these groups might be obtained by cycle formation of $\mathrm{N}$-groups from amino acids with protein origin during pyrolysis, because they have not been detected in HS by ${ }^{15} \mathrm{~N}$ NMR (38). This fact is corroborated by a high correlation between $\mathrm{N}$-compounds measured by pyrolysis GCMS and O-alkyl-C and carbonyl-C (amino acidic markers) by ${ }^{13} \mathrm{C}$ NMR $(R=0.71$ and $R=0.82$, respectively). 
Table 5. Statistical Correlation $(R)$ between Pyrolysis GC-MS and ${ }^{13} \mathrm{C}$ NMR Values for the Different Humic Fractions ${ }^{a}$

\begin{tabular}{|c|c|c|c|c|c|c|c|c|c|c|c|}
\hline & PS & $\mathrm{N}$ & TPh & TAR & $A L$ & $S$ & alkyl-C & O-alkyl-C & arom-C & phenol-C & carbonyl-C \\
\hline PS & 1 & 0.57 & 0.42 & 0.09 & -0.58 & -0.15 & -0.59 & 0.61 & -0.16 & 0.39 & $0.91^{* *}$ \\
\hline $\mathrm{N}$ & 0.57 & 1 & 0.29 & 0.04 & -0.39 & 0.09 & -0.42 & $0.71^{*}$ & -0.38 & 0.38 & $0.82^{*}$ \\
\hline TPh & 0.42 & 0.29 & 1 & 0.60 & $-0.78^{*}$ & 0.62 & $-0.83^{*}$ & 0.55 & 0.45 & $0.97^{\star *}$ & 0.53 \\
\hline TAR & 0.09 & 0.04 & 0.60 & 1 & $-0.84^{\star *}$ & 0.56 & $-0.81^{*}$ & 0.32 & $0.77^{*}$ & 0.52 & 0.22 \\
\hline $\mathrm{AL}$ & -0.58 & -0.39 & $-0.78^{*}$ & $-0.84^{\star \star}$ & 1 & -0.50 & $0.99^{\star *}$ & -0.64 & -0.54 & $-0.73^{\star}$ & -0.66 \\
\hline$S$ & -0.15 & 0.09 & 0.62 & 0.56 & -0.50 & 1 & -0.51 & 0.21 & 0.57 & $0.72^{*}$ & -0.019 \\
\hline alkyl-C & -0.59 & -0.42 & $-0.83^{*}$ & $-0.81^{*}$ & $0.99^{\star *}$ & -0.51 & 1 & -0.59 & -0.56 & $-0.79^{*}$ & -0.69 \\
\hline O-alkyl-C & 0.61 & $0.71^{*}$ & 0.55 & 0.32 & -0.64 & 0.21 & -0.59 & 1 & -0.26 & 0.51 & $0.74^{*}$ \\
\hline arom-C & -0.16 & -0.38 & 0.45 & $0.77^{*}$ & -0.54 & 0.57 & -0.56 & -0.26 & 1 & 0.42 & -0.14 \\
\hline phenol-C & 0.39 & 0.38 & $0.97^{\star \star}$ & 0.52 & -0.73 & $0.72^{*}$ & $-0.79^{*}$ & 0.51 & 0.42 & 1 & 0.52 \\
\hline carbonyl-C & $0.91^{* *}$ & $0.82^{*}$ & 0.53 & 0.22 & -0.66 & -0.02 & -0.69 & $0.74^{*}$ & -0.14 & 0.52 & 1 \\
\hline
\end{tabular}

${ }^{a} \mathrm{TPh}=$ phenols + guaiacols + syringols. TAR $=$ phenols + guaiacols + syringols + alkylbenzenes + PAHs $.{ }^{*}, p<0.05 ;{ }^{* *}, p<0.01$

Sulfur compounds accumulate in BHA and SRFA, thus suggesting that they do not have a dominant lipidic character, in contrast to the results reported by Saiz-Jiménez (42). This result is corroborated by the fact that sulfur markers were well correlated with phenol-C $(R=0.72)$ and negatively correlated with the aliphatic content by pyrolysis GC-MS and ${ }^{13} \mathrm{C}$ NMR ( $R=-0.50$ and $R=-0.51$, respectively).

The high consistency between the information derived from pyrolysis GC-MS and ${ }^{13} \mathrm{C}$ NMR that is reflected in the high correlation among the structural markers corresponding to both techniques (TPh and phenol-C, and $\mathrm{AL}$ and alkyl-C, also presented high correlation: $R=0.97$ and 0.99 , respectively), indicating the high complementarity of both techniques.

In consequence, the information obtained from the complementary use of TGA, pyrolysis GC-MS, and ${ }^{13} \mathrm{C}$ NMR (and also FTIR) clearly shows that the different HS fractions studied (GHA, BHA, and FA) have different and distinctive structural features. Thus, large and nonpolar structural domains (paraffins, olefins, terpenes) and aliphatic structures seem to accumulate in the gray fraction, whereas the smallest and more polar (furfural, phenols) and simpler structures (sugar-, amino acidrelated structures) are present in the fulvic one. The brown humic fraction presents a higher content in PAHs, furans, and Scontaining compounds and aromatic structures, thus suggesting the presence of more condensed aromatic rings and polysaccharides. Differences in the polar character of each humic fraction considered together with their apparent molecular size explain the pattern of solubility as a function of $\mathrm{pH}$ and $I$ that defines each HS fraction. However, these results also indicate that the structural differences between each fraction are not only quantitative (the presence of the same type of structure differing in size and the concentration of functional groups) but also qualitative because each fraction corresponds to a different and distinctive structural pattern. These structural patterns explain their associated molecular ones. In this sense, the presence of smaller and more O-functionalized structural units and aromatic domains in FA explains their tendency to form molecular aggregates (hydrogen bridges, metal bridges, hydrophobic effect) in solution (supramolecular pattern). This fact could also explain the presence of molecular aggregates in BHA, although to a lesser extent than in FA. Finally, the dominant aliphatic and less functionalized character of GHA may justify their lower tendency to form aggregates in solution at neutral and alkaline $\mathrm{pH}$ (macromolecular pattern).

To investigate the possible degradation pathways associated with each HS fraction, we have calculated two different indices of the biodegradation degree. The first one is the syringol-toguaiacol ratio $(38,40,41)$, which refers to the biodegradation of lignin. Guaiacol units are more resistant to degradation by microorganisms than syringol $(40,41)$, and therefore, the higher the value of this ratio, the lower the biodegradation undergone by the humic fraction. Both guaiacol and syringol units were present in the pyrolysates of FA, whereas syringols were absent in the pyrolysates of both BHA and GHA (Table 4). According to this index, GHA would be more biodegraded than BHA, and FA would be less biodegraded. The second index of biodegradation is based on the alkane + alkene content, originated from hydrocarbons with high resistance to degradation $(38,42,45)$. Thus, the samples with higher alkane + alkene content would be less biodegraded. The results are presented in Table 4 . In this case the values of this index indicate the following order of degradation: FA > BHA > GHA.

In principle, the contradictory conclusions derived from these two indices may be explained by both the presence of different organic precursors for each molecular fraction and diverse biosynthetic pathways. Thus, the different structural domains associated with these fractions may be the consequence of diverse biosynthetic pathways involving different precursors.

Finally, these results reinforce the practical and theoretical interest of the classical HS classification in gray humic acids, brown humic acids, and fulvic acids. This taxonomy is not only valid, but it has the advantage of discriminating different structural domains typical of each fraction, making easier the knowledge of the molecular composition of HS and their complexity. In addition, it may be used for establishing relationships between the structure of HS systems and their environmental role in different ecosystems.

\section{ACKNOWLEDGMENT}

We thank David Rhymes for kindly improving the English of the paper.

\section{LITERATURE CITED}

(1) Stevenson, F. J. Humus Chemistry: Genesis, Composition, Reactions; Wiley: New York, 1994.

(2) Wershaw, R. Model for humus in soils and sediments. Environ. Sci. Technol. 1993, 27, 814-816.

(3) Schnitzer, M. Soil organic matter-The next 75 years. Soil Sci. 1991, 151, 41-58.

(4) Swift, R. S. In Humic Substances in Soil, Sediment and Water; Aiken, G. R., McKnight, D. M., Wershaw, R. L., MacCarthy, P., Eds.; Wiley-Interscience: New York, 1985; pp 392-393.

(5) Orlov, D. S. Humus Acids of Soils; A. A. Balkema: Rotterdam, The Netherlands, 1985.

(6) Kumada, K. Chemistry of Soil Organic Matter; Japan Scientific Societies Press and Elsevier: Tokyo, Japan, 1987.

(7) Álvarez-Puebla, R. A.; Valenzuela-Calahorro, C.; Garrido, J. J. Retention of $\mathrm{Co}(\mathrm{II}), \mathrm{Ni}(\mathrm{II})$, and $\mathrm{Cu}(\mathrm{II})$ on a purified brown humic acid. Modeling and characterization of the sorption process. Langmuir 2004, 20, 3657-3664. 
(8) Álvarez-Puebla, R. A.; Goulet, P. J. G.; Garrido, J. J. Characterization of the porous structure of different humic fractions. Colloids Surf. A: Physicochem. Eng. Aspects 2005, 256, 129135.

(9) Álvarez-Puebla, R. A.; Garrido, J. J.; Valenzuela-Calahorro, C.; Goulet, P. J. G. Retention and induced aggregation of $\mathrm{Co}(\mathrm{II})$ on a humic substance: sorption isotherms, infrared absorption, and molecular modeling. Surf. Sci. 2005, 575, 136-146.

(10) Álvarez-Puebla, R. A.; Garrido, J. J. Effect of $\mathrm{pH}$ on the aggregation of a gray humic acid in colloidal and solid states. Chemosphere 2005, 59, 659-667.

(11) Baigorri, R.; Fuentes, M.; González-Gaitano, G.; García-Mina, J. M. Simultaneous presence of diverse molecular patterns in humic substances in solution. J. Phys. Chem. B 2007, 111, 1057710582.

(12) Novotny, E. H.; Blum, W. E. H.; Gerzabek, M. H.; Mangrich, A. S. Soil management system effects on size fractionated humic substances. Geoderma 1999, 92, 87-109.

(13) Knicker, H.; González-Vila, F. J.; Polvillo, O.; González, J. A.; Almendros, G. Fire-induced transformation of C- and $\mathrm{N}$-forms in different organic soil fractions from a Dystric Cambisol under a Mediterranean pine forest (Pinus pinaster). Soil Biol. Biochem. 2005, 37, 701-718.

(14) Baigorri, R.; Zamarreño, A. M.; Fuentes, M.; González-Gaitano, G.; García-Mina, J. M.; Almendros, G.; González-Vila, F. J. Multivariate statistical analysis of mass spectra as a tool for the classification of humic substances according to their structural and conformational features. J. Agric. Food Chem. 2008, 56, 5480-5487.

(15) Novák, J.; Kozler, J.; Janoš, P.; Čežiková, J.; Tokarová, V.; Mandronová, L. Humic acids from coals of the Noth-Bohemian coal field I. Preparation and characterization. React. Funct. Polym. 2001, 47, 101-109.

(16) Switf, R. S. In Methods of Soil Analysis. Part 3. Chemical Methods; Sparks, D. L., Ed.; Soil Science Society of America: Madison, WI, 1996.

(17) Gerard, C.; Njomgang, R.; Hugel, R. P. Complexes du fer(III) avec des molécules modèles d'acides humiques de synthèse. Essai d'interprétation de titrages protométriques. Sci. Sol. 1990, 28, 161174.

(18) Barančíková, G.; Senesi, N.; Brunetti, G. Chemical and spectroscopic characterization of humic acids isolated from different Slovak soil types. Geoderma 1997, 78, 251-266.

(19) Davies, G.; Fataftah, A.; Cherkasskiy, A.; Ghabbour, E. A.; Radwan, A.; Jansen, S. A.; Kolla, S.; Paciolla, M. D.; Sein, L. T.; Buermann, W.; Balasubramanian, M.; Budnick, J.; Xing, B. Tight metal binding by humic acids and its role in biomineralization. J. Chem. Soc., Dalton Trans. 1997, 21, 4047-4060.

(20) Rivero, C.; Senesi, N.; Paolini, J.; D’Orazio, V. Characteristics of humic acids of some Venezuelan soils. Geoderma 1998, 81, 227-239.

(21) Shing, H.-S.; Monsallier, J. M.; Choppin, G. R. Spectroscopic and chemical characterization of molecular size fractionated humic acid. Talanta 1999, 50, 641-647.

(22) Davis, W. M.; Erickson, C. L.; Jonhston, C. T.; Delfino, J. J.; Porter, J. E. Quantitative Fourier transform infrared spectroscopic investigation of humic substance functional group composition. Chemosphere 1999, 38, 2913-2928.

(23) Ricca, G.; Severini, F.; Di Silvestro, G.; Yuan, C. M.; Adani, F. Derivatization and structural studies by spectroscopic methods of humic acids from Leonardite. Geoderma 2000, 98, 115-125.

(24) Tanaka, T.; Nagao, S.; Ogawa, H. Attenuated total refection Fourier transform infrared (ATR-FTIR) spectroscopy of functional groups of humic acid dissolving in aqueous solution. Anal. Sci. 2001, 17, i1081-i1084.

(25) Senesi, N.; D'Orazio, V.; Rica, G. Humic acids in the first generation of EUROSOILS. Geoderma 2003, 116, 325-344.

(26) Chen, Y.; Taschitzky, J.; Markovitch, O. Humic Susbtances-Linking Structure to Functions; Frimmel, F. H., Abbt-Braun, G., Eds.; Karlsruhe, Germany, 2006.
(27) Shurygina, E. A.; Larina, N. K.; Chubarova, M. A.; Kononova, M. M. Differential thermal analysis (DTA) and thermogravimetry (TG) of soil humus substances. Geoderma 1971, 6, 169-177.

(28) Kučerik, J.; Kovář, J.; Pekař, M. Thermoanalytical investigation of lignite humic acids fractions. J. Therm. Anal. Cal. 2004, 76, $1-11$.

(29) Schnitzer, M.; Hoffman, I. Thermogravimetry of soil humic compounds. Geochim. Cosmochim. Acta 1965, 29, 859-870.

(30) González-Pérez, J. A.; González-Vila, F. J.; Almendros, G.; Knicker, H. The effect of fire on soil organic matter-a review. Environ. Int. 2004, 30, 855-870.

(31) Almendros, G.; Dorado, J.; González-Vila, F. J.; Martín, F. Pyrolysis of carbohydrate-derived macromolecules: its potential in monitoring the carbohydrate signature of geopolymers. J. Anal. Appl. Pyrolysis 1997, 40-41, 599-610.

(32) González-Vila, F. J.; Tinoco, P.; Almendros, G.; Martín, F. Formation and degradation stages of melanoidins analogous to humic substances in charred residues from lignocelulosic biomass. Biomass. J. Agric. Food Chem. 2001, 49, 1128-1131.

(33) Baldock, J. A.; Smernik, R. J. Chemical composition and bioavailability of thermally altered Pinus resinosa (red pine) wood. Org. Geochem. 2002, 33, 1093-1109.

(34) Almendros, G.; Knicker, H.; Gonzalez-Vila, F. J. Rearrangement of carbon and nitrogen forms in peat after progressive thermal oxidation as determined by solid-state ${ }^{13} \mathrm{C}$ - and ${ }^{15} \mathrm{~N}-\mathrm{NMR}$ spectroscopy. Org. Geochem. 2003, 34, 1559-1568.

(35) Knicker, H.; Almendros, G.; González-Vila, F. J.; Martín, F.; Lüdemann, H.-D. ${ }^{13} \mathrm{C}$ - and ${ }^{15} \mathrm{~N}-\mathrm{NMR}$ spectroscopic examination of the transformation of organic nitrogen in plant biomass during thermal treatment. Soil Biol. Biochem. 1996, 28, 1053-1060.

(36) Kramer, R. W.; Kujawinski, E. B.; Hatcher, P. G. Identification of black carbon derived structures in a volcanic ash soil humic acid by fourier transform ion cyclotron resonance mass spectrometry. Environ. Sci. Technol. 2004, 38, 3387-3395.

(37) Haumaier, L.; Zech, W. Black carbon-possible source of highly aromatic components of soil humic acids. Org. Geochem. 1995, 23, 191-196.

(38) Chefetz, B.; Chen, Y.; Clapp, C. E.; Hatcher, P. G. Characterization of organic matter in soils by thermochemolysis using tetramethylammonium hydroxide (TMAH). Soil Sci. Soc. Am. J. 2000, 64, 583-589.

(39) Tinoco, P.; Almendros, A.; González-Vila, F. J. Impact of the vegetation on the lignin pyrolitic signature of soil humic acids from Mediterranean soils. J. Anal. Appl. Pyrolysis 2002, 64, 407420.

(40) Dignac, M.-F.; Houot, S.; Derenne, S. How the polarity of the separation column may influence the characterization of compost organic matter by pyrolysis-GC/MS. J. Anal. Appl. Pyrolysis 2006, 75, 128-139.

(41) Fabbri, D.; Sangiorgi, F.; Vassura, I. Pyrolysis-GC-MS to trace terrigeneous organic matter in marine sediments: a comparison between pyrolytic and lipid markers in the Adriatic Sea. Anal. Chim. Acta 2005, 530, 253-261.

(42) Saiz-Jiménez, C.; de Leeuw, J. W. Chemical structure of a soil humic acid as revealed by analytical pyrolysis. J. Anal. Appl. Pyrolysis 1987, 11, 367-376.

(43) Parsi, Z.; Hargot, N.; Górecki, T.; Poerschmann, J. Analytical pyrolysis as a tool for the characterization of natural organic matter-a comparison of different approaches. J. Anal. Appl. Pyrolysis 2006, 79, 9-15.

(44) Almendros, G.; González-Vila, F. J.; Martín, F.; Sanz, J.; ÁlvarezRamis, C. Appraisal of pyrolytic techniques on different forms of organic matter from a Cretaceous basement in central Spain. Org. Geochem. 1998, 28, 613-623.

(45) Saiz-Jiménez, C. Reactivity of the aliphatic humic moiety in analytical pyrolysis. Org. Geochem. 1995, 23, 955-961.

Received for review November 11, 2008. Revised manuscript received February 6, 2009. Accepted February 9, 2009.

JF8035353 